\title{
Efficacy of Using PDGF and Xenograft With or Without Collagen Membrane for Bone Regeneration Around Immediate Implants With Induced Dehiscence-Type Defects: A Microcomputed Tomographic Study in Dogs
}

Bann Ahmad Al-Hazmi, ${ }^{* \dagger}$ Khalid Saleh Al-Hamdan, ${ }^{* \dagger}$ Abdulaziz Al-Rasheed, ${ }^{* \dagger}$ Nadir Babay, ${ }^{\dagger}$ Hom-Lay Wang, ${ }^{\dagger}$ and Khalid Al-Hezaimi* ${ }^{\dagger}$

Background: Use of collagen membrane (CM) with xenograft and recombinant human platelet-derived growth factor (rhPDGF) in guided bone regeneration (GBR) is debatable. The aim of this microcomputed tomographic experiment was to assess the efficacy of using PDGF and xenograft (with or without CM) for GBR around immediate implants with dehiscence defects.

Methods: Ten beagle dogs underwent atraumatic bilateral second and fourth premolar extractions from both arches. A standardized dehiscence defect $(6 \times 3 \mathrm{~mm})$ was created on the buccal bone and immediate implants were placed in distal sockets in each site. Animals were randomly divided into three groups: 1) group 1, xenograft with rhPDGF was placed and covered with CM; 2) group 2, xenograft with rhPDGF was placed over the defects; and 3) group 3, four immediate implants were associated with dehiscence (controls). After 16 weeks, animals were sacrificed and jaw segments were assessed for buccal bone thickness (BBT), buccal bone volume (BBV), vertical bone height (VBH), and bone-to-implant contact (BIC) using microcomputed tomography.

Results: BBT was higher in group $2(1.533 \pm 0.89 \mathrm{~mm})$ than group $1(0.745 \pm 0.322 \mathrm{~mm})(P<0.001)$ and group $3(0.257 \pm 0.232 \mathrm{~mm})(P<0.05)$. BBV was higher in group $2\left(67.87 \pm 19.83 \mathrm{~mm}^{3}\right)$ than group $1\left(42.47 \pm 6.78 \mathrm{~mm}^{3}\right)(P<0.05)$ and group $3\left(19.12 \pm 4.06 \mathrm{~mm}^{3}\right)(P<0.001)$. VBH was higher in group $2(6.36 \pm 1.37 \mathrm{~mm})$ than group $3(0.00 \pm 0.00 \mathrm{~mm})(P<0.001)$. VBH was higher in group 1 $(3.91 \pm 2.68 \mathrm{~mm})$ than group $3(0.00 \pm 0.00 \mathrm{~mm})(P<0.05)$. BIC was higher in group $2(67.25 \% \pm$ $13.42 \%)$ than group $1(36.25 \% \pm 12.78 \%)(P<0.05)$ and group $3(30.25 \% \pm 7.27 \%)(P<0.01)$.

Conclusion: GBR around immediate implants with dehiscence defects using PDGF and xenograft alone resulted in higher BBT, BBV, VBH, and BIC than when performed in combination with CM. J Periodontol 2013;84:371-378.

\section{KEY WORDS}

Bone regeneration; dental implants; membranes; platelet-derived growth factor; x-ray microtomography.

\footnotetext{
* Engineer Abdullah Bugshan Research Chair for Growth Factors and Bone Regeneration, College of Dentistry \& Applied Biomedical Sciences, King Saud University, Riyadh, Saudi Arabia.

$\dagger$ Department of Periodontics and Community Dentistry, King Saud University.

† Division of Periodontics, Department of Periodontics and Oral Medicine, University of Michigan School of Dentistry, Ann Arbor, MI.
} 
I $\mathrm{t}$ is well acknowledged that the buccal process of alveolar bone is entirely composed of bundle bone and is therefore more susceptible to undergo resorption after tooth extraction compared to the lingual/palatal process. ${ }^{1-8}$ Nevins et al. ${ }^{9}$ reported that $\geq 20 \%$ of the buccal process of alveolar bone undergoes resorption within the first 12 weeks of tooth loss, whereas studies by Schropp et al. ${ }^{7,8}$ reported that nearly $66 \%$ of the alveolar bone undergoes resorption within the first 3 months of tooth extraction. Results from a recent histologic study ${ }^{4}$ on baboons emphasized that the buccal bone receives an essential share of its vascular supply from the adjacent interdental bone and not merely from the socket side of the alveolus. This study ${ }^{4}$ also showed that extraction of multiple contiguous teeth is associated with a more intense alveolar bone remodeling around extraction sites because the interdental vascular supply is compromised to a much larger extent compared to when a single tooth is extracted. It has been reported that immediate implant placement in fresh extraction sites may prevent alveolar bone remodeling in the short term; ${ }^{10,11}$ however, localized osseous defects around immediate implants placed in fresh extraction sites may present a challenge to the clinician. ${ }^{12}$

Guided bone regeneration (GBR) using barrier membranes has been applied in implant dentistry for increasing the width and height of the alveolar ridge in areas with insufficient bone. ${ }^{9-13}$ Various combinations of resorbable membranes and bone grafts, such as collagen membranes (CMs) with demineralized freeze-dried bone allograft, CMs with deproteinized bovine bone, and dermal matrix membranes with bioactive glass have been used in GBR. ${ }^{14,15}$ Although studies $^{16,17}$ have reported that placement of a barrier membrane over the bone grafts during GBR favors new bone formation around immediate implants, the contribution of resorbable membranes during GBR using xenografts and growth factors is unclear.

Growth factors are polypeptide hormones that regulate the cellular events associated with tissue regeneration and repair. ${ }^{18-20}$ The platelet-derived growth factor (PDGF) has been comprehensively assessed with reference to periodontal regeneration. ${ }^{19-24}$ Studies ${ }^{19-24}$ have demonstrated that PDGF endorses formation of new bone tissues around immediate implants with periodontal bony defects in the presence, as well as absence, of barrier membranes. The present study is based on the null hypothesis that use of a resorbable barrier membrane during GBR with PDGF and xenograft does not enhance the buccal bone thickness (BBT), buccal bone volume (BBV), vertical bone height (VBH), and bone-to-implant contact (BIC) around immediate implants with buccal dehiscence-type defects.
The present microcomputed tomographic analysis aims to assess the efficacy of using PDGF and xenograft (either with or without a CM) on GBR around immediate implants with dehiscence-type defects in a canine model.

\section{MATERIALS AND METHODS}

\section{Ethical Considerations}

The study was approved by the ethical committee at the Engineer Abdullah Bugshan Research Chair for Growth Factors and Bone Regeneration (GFBR), King Saud University, Riyadh, Saudi Arabia. Preoperative animal care, all surgical procedures, and postoperative management of the animals were performed in accordance with the Animal Care Guidelines of GFBR.

\section{Study Animals}

Ten female beagle dogs with a mean age and weight of $19 \pm 1$ months and $13.8 \pm 1.00 \mathrm{~kg}$, respectively, were used. The animals were kept in individual cages and vaccinated against rabies and infectious hepatitis.

The non-surgical and surgical procedures were performed under general anesthesia§ $(10 \mathrm{mg} / \mathrm{kg}$ body weight).

\section{Preoperative Management}

During the housing period, the dogs underwent supragingival scaling twice a week for 3 weeks using an ultrasonic scaler. Intramuscular amoxicillin"l (25 $\mathrm{mg} / \mathrm{kg}$ body weight) was administered 1 day before surgery, followed by a second dose of the same antibiotic" $^{\#}$ at the time of surgery.

\section{Animal Grouping and Treatment of Dehiscence Defects}

The animals were randomly divided into three groups (by picking a paper marked "group 1," "group 2," or "group 3" from a brown bag). Animal grouping was based on the methodology adopted for the treatment of dehiscence defects: 1) group 1 (18 defects), in which xenograft** soaked in recombinant human (rh) PDGF-BB ${ }^{\dagger \dagger}$ was placed over the defects and covered with a CM; ${ }^{\ddagger}$ 2) group 2 (18 defects), in which xenograft $\S \S$ was soaked in rhPDGF-BBIIII and placed over the defects; and 3) group 3 (four defects), in which four immediate im-

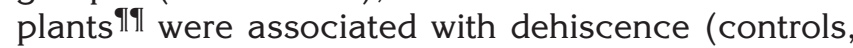
no treatment). In group 1 and group 2, $0.5 \mathrm{~mL}$ of 0.3

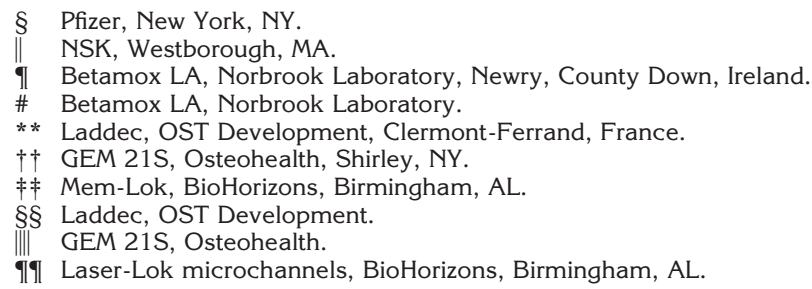



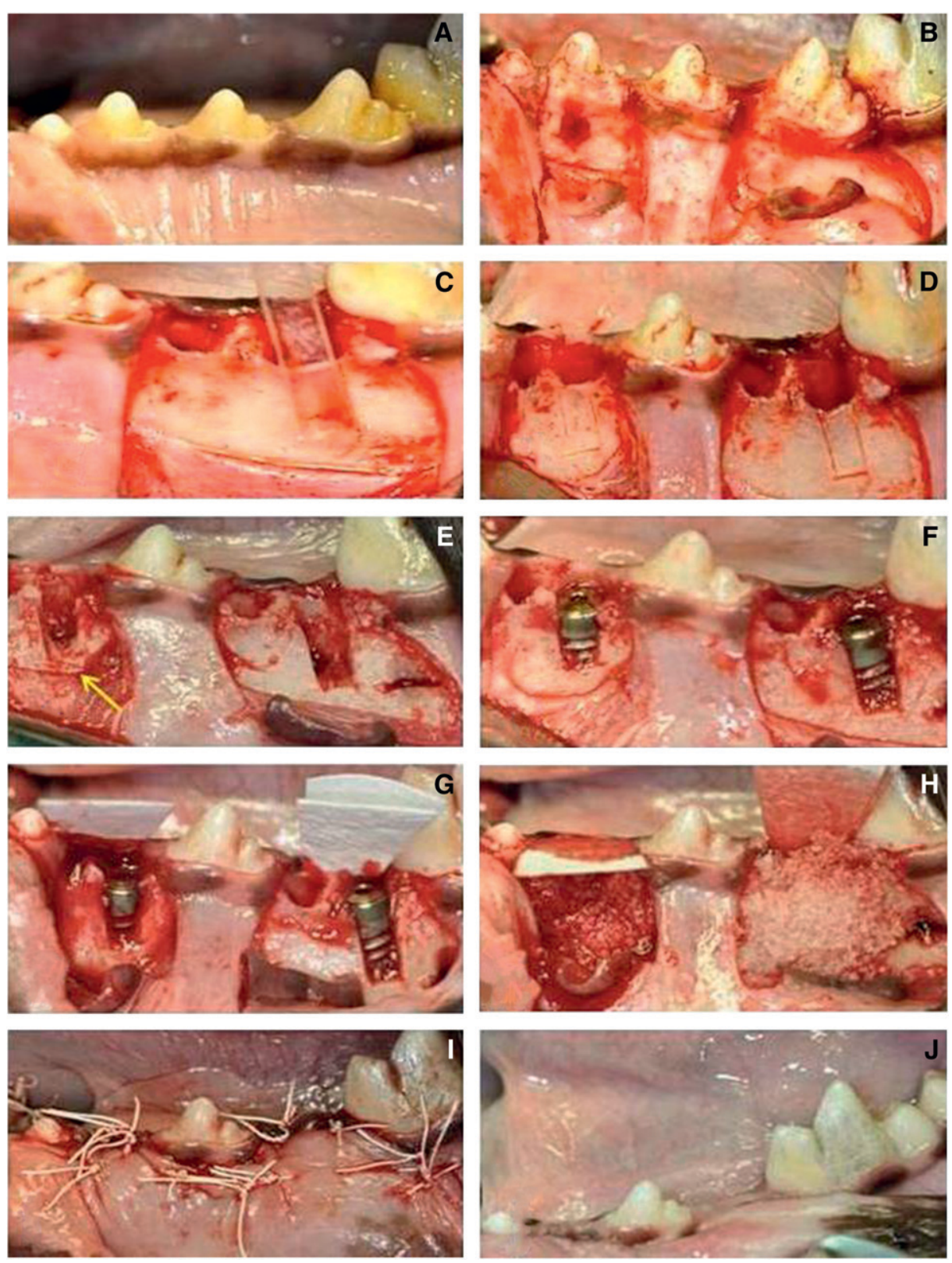

Figure 1 .

A) Preoperative photograph; B) elevation of full-thickness mucoperiosteal flaps; C) placement of stent on the buccal wall for creation of critical size defect; $\mathbf{D})$ critical size defect $(3 \times 6 \mathrm{~mm})$; $\boldsymbol{E})$ placement of notch (yellow arrow); $\boldsymbol{F}$ ) immediate implant placement; $\mathbf{G}$ ) adaptation of $\mathrm{CM} ; \boldsymbol{H})$ placement of xenograft; I) suturing; and J) I-month follow-up photograph.

$\mathrm{mg} / \mathrm{mL}$ rhPDGF was delivered using the particulate xenograft. ${ }^{\# 22}$

\section{Surgical Protocol}

After general anesthesia (as described above), animals were draped, and the surgical sites were swabbed with an antiseptic solution.*** Local anesthesia ${ }^{\dagger \dagger \dagger}$ was administered in the bilateral premolar regions of both arches. Teeth (second premolar [P2] and fourth premolar [P4]) were atraumatically extracted using piezosurgery. ${ }^{\ddagger \ddagger}$ All buccal and lingual/palatal bone was sound with no dehiscence. Using a sulcular incision (with a no. 15 blade), full-thickness buccal and lingual/palatal flaps were raised to the mucogingival junction, after which a partial-thickness flap was raised to allow passive closure. Two vertical incisions (one mesial and one distal) were made. In each quadrant, P2 and P4 were extracted. A standardized hard acrylic stent $\$ \S \S$ was used to create a dehiscence bony defect $(3 \times$ $6 \mathrm{~mm}$ ) on the buccal surface of the extraction socket (Fig. $1)$. This was followed by immediate implant ${ }^{t\|\|}(3.8 \times 10.5$ $\mathrm{mm}$ ) placement in the distal extraction sockets (Fig. 1) and assignment of this site to one of the three groups. The surgical wounds were sutured बीाt to achieve primary closure.

\section{Postoperative \\ Management and \\ Euthanasia}

All animals received intramuscular (IM) injections of

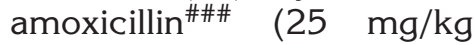
body weight) every 8 hours for 5 days. Analgesics **** ( 0.01 to $0.02 \mathrm{mg} / \mathrm{kg}$, IM) were administered immediately after surgery and every 8 hours for the first 2 days after surgery and then whenever needed depending on the presence of signs of pain by the animal (such as restlessness, unusual calmness, or refusal to eat). Plaque control procedures, using topical application of a $0.2 \%$ chlorhexidine digluconate solution, ${ }^{\dagger \dagger \dagger \dagger}$ were

\footnotetext{
\#\# Laddec, OST Development.

*** Purdue Fredrick Company, Stamford, CT

$\dagger \dagger \dagger \quad$ Astra, Westborough, MA

俦 Mectron, Piezosurgery, Columbus, $\mathrm{OH}$.

$\S \S \S$ Ellman International, Oceanside, NY.

IIIII Laser-Lok microchannels, BioHorizons.

Tाๆๆ Gore-Tex, W.L. Gore \& Associates, Flagstaff, AZ

\#\#\# Buprenorphine, SR Veterinary Technologies, Windsor, CO.

**** GUM, Sunstar GUM, Chicago, IL.

$\dagger \dagger \uparrow \dagger$ Gore-Tex, W.L. Gore \& Associates.
} 

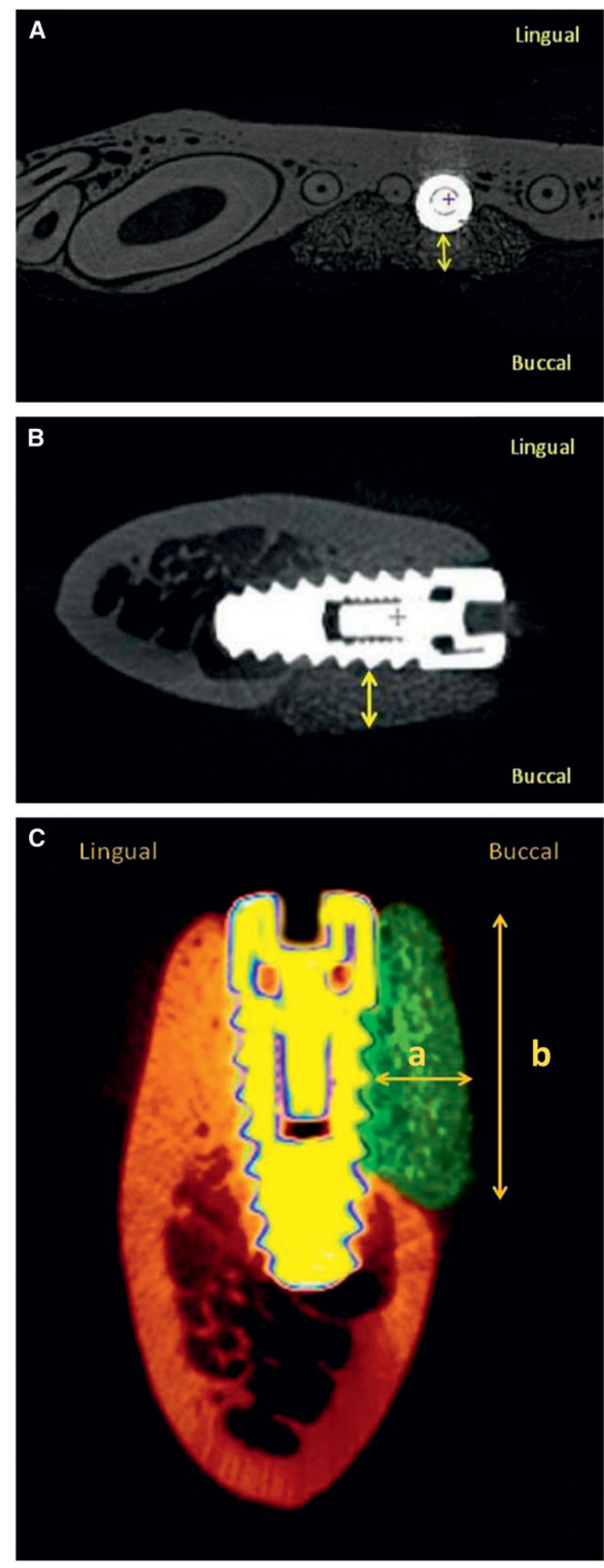

Figure 2.

Measurement of BBT (yellow arrows) around immediate implants: $\boldsymbol{A}$ ) axial view and $\mathbf{B}$ ) sagittal view. C) Measurement of BBT (a) and VBH (b). performed twice weekly for 4 months after surgery. Sutures ${ }^{\neq \neq \neq \neq \neq}$were removed after 10 days of surgery, and the animals were kept on a soft diet throughout the study period.

After 4 months, the animals were sacrificed with an intravenous overdose of 3\% sodium pentobarbital.§§§§

\section{Hard-Tissue Sectioning and Microcomputed Tomography}

The jaw segments containing the dental implants and associated mesial and distal tooth structures were removed en bloc using an electric saw $\|$ |lll|l and fixed in $10 \%$ neutral formalin solution.

A microcomputed tomography (microCT) scanner ITाTा was used to evaluate the BBT, BBV, VBH, and BIC around immediate implants. The $\mathrm{x}$-ray generator of the microCT was operated at an accelerated potential of $101 \mathrm{kV}$ with a beam current of $96 \mu \mathrm{A}$ using an aluminum filter with a resolution of $37.41-\mu \mathrm{m}$ pixels. The BBT was measured at every 1 -mm level starting from the alveolar crest to the base of the defect (Figs. $2 \mathrm{~A}$ and $2 \mathrm{~B}$ ). The BBV was measured as described in a recent study. ${ }^{25}$ In the adjacent teeth, VBH was measured via linear measurements (in millimeters) that extended from the crest of the implant to the apical notch (Fig. 2C). For BIC measurement, the total surface area of the region of interest (ROI) and the subset of the ROI surface that was intersected by binarized bone objects was measured via an analysis software..$^{3,26}$ The parameter thus measured was called "intersection surface" that corresponded to $\mathrm{BIC}$. The BIC was calculated (at $\times 100$ magnification) as the percentage of implant surface in contact with the bone through the whole perimeter of the implant. ${ }^{3,26}$

\section{Statistical Analyses}

Statistical analyses were performed using a statistical software. ${ }^{\# \# \# \# ~ T h e ~ p o w e r ~ o f ~ t h e ~ p r e s e n t ~ s t u d y ~ w a s ~}$ 95\% (common standard deviation of $1 \mathrm{~mm}$ and $\alpha=$ $0.05)$. One-way analysis of variance was used to determine the differences in means of the BBT, BBV, $\mathrm{VBH}$, and BIC among the groups. $P$ values 0.05 were considered to be statistically significant. The data were normally distributed.

\section{RESULTS}

\section{$B B T$}

The mean BBT was significantly higher around dehiscence defects in group $2(1.533 \pm 0.89 \mathrm{~mm})$ compared to that in group $1(0.745 \pm 0.322 \mathrm{~mm})$ $(P<0.01)$ and group $3(0.257 \pm 0.232 \mathrm{~mm})(P<0.05)$. There was no significant difference in the BBT

キキキキ W.A. Butler Company, Dublin, OH.

$\S \S \S \S$ SP 1600, Leica, Bannockburn, IL.

IIIIII SkyScan 1172, CT-Analyser v.1.11.4.2+, Skyscan, Kontich, Belgium. ๆๆๆ nQuery Advisor v.7.0, Statistical Solutions, Saugus, MA. 
A

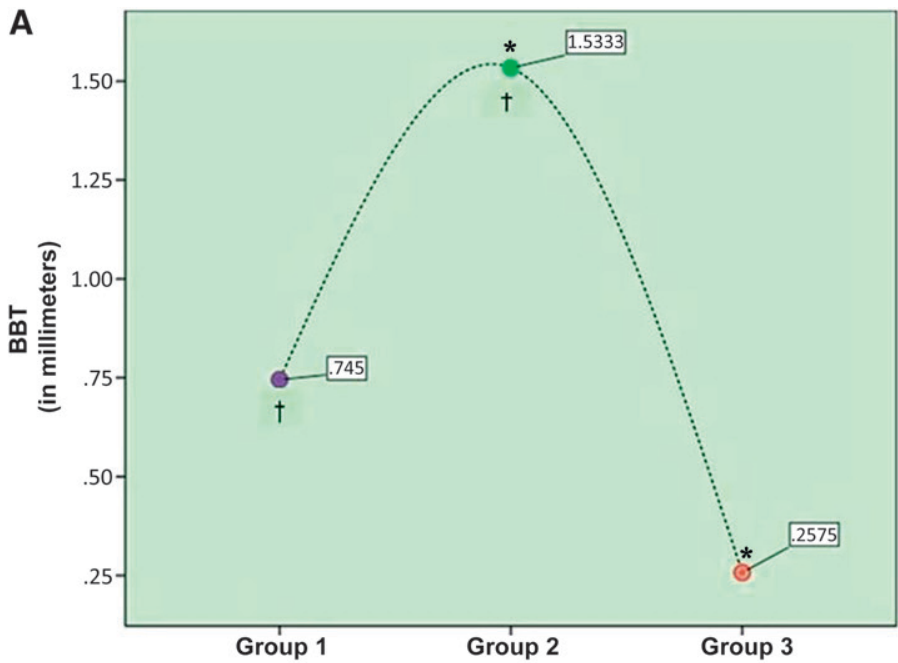

C

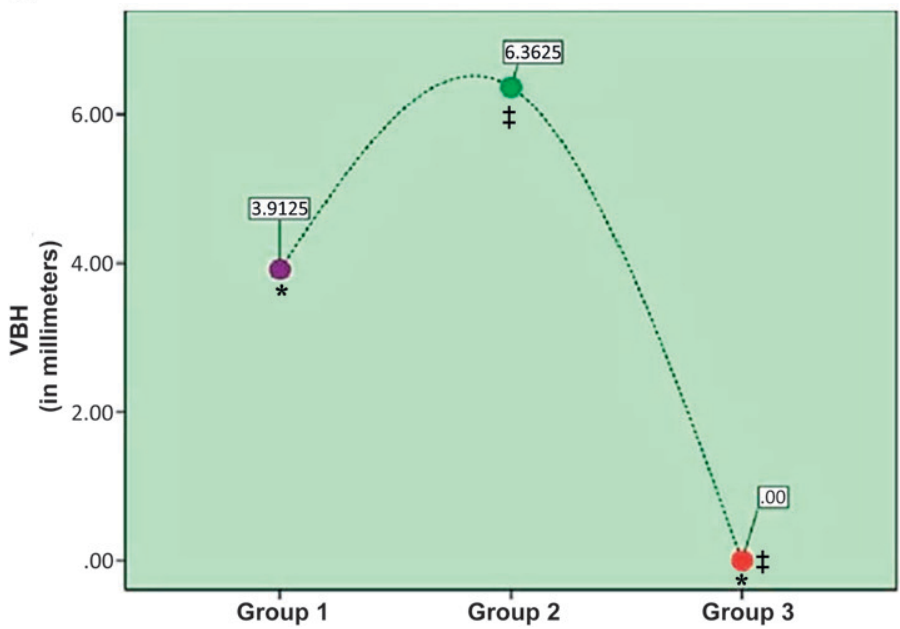

B

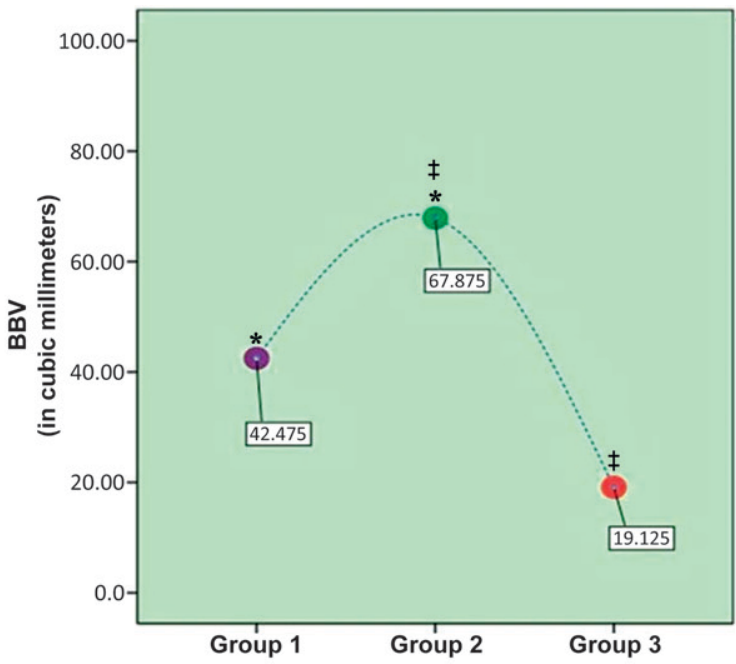

D

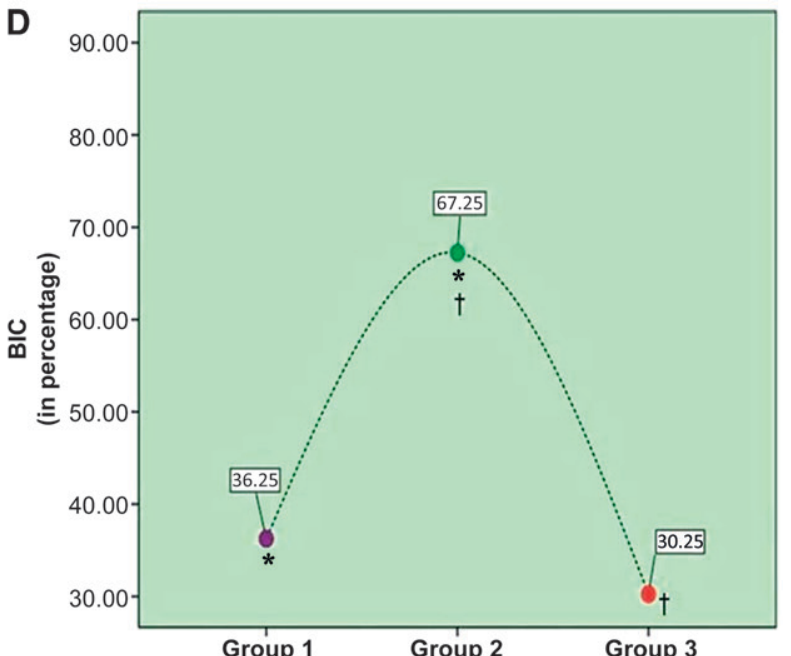

Figure 3.

A) A graphic representation of the BBT around immediate implants with dehiscence in sites in group I (purple circle: PDGF + xenograft +CM), group 2 (green circle: PDGF + xenograft), and group 3 (orange circle: control/no treatment). BBT was significantly higher among sites in group 2 compared to sites in group I $(\mathrm{P}<0.01)$ and group $3(\mathrm{P}<0.05)$. ${ }^{*} \mathrm{P}<0.05 ;{ }^{\dagger} \mathrm{P}<0.01$. B) A graphic representation of the $\mathrm{BBV}$ around immediate implants with dehiscence among sites in group I (purple circle: PDGF + xenograft $+C M$ ), group 2 (green circle: PDGF + xenograft) and group 3 (orange circle: control/no treatment). BBV was significantly higher among sites in group 2 compared to those in group I ( $P<0.05)$ and group $3\left(P<0.00\right.$ I). $* P<0.05 ;{ }^{\ddagger} \mathrm{P}<0.00$ I. C) A graphic representation of the VBH around immediate implants with dehiscence among sites in group I (purple circle: PDGF + xenograft + CM), group 2 (green circle: PDGF + xenograft), and group 3 (orange circle: control/no treatment). VBH was significantly higher among sites in group 2 compared to those in group I $(\mathrm{P}<0.05)$ and group $3\left(\mathrm{P}<0.00\right.$ I). ${ }^{*} \mathrm{P}<0.05 ;{ }^{*} \mathrm{P}<0.00$ I. D) A graphic representation of the $\mathrm{BIC}$ around immediate implants with dehiscence among sites in group I (purple circle: PDGF + xenograft $+C M$ ), group 2 (green circle: PDGF + xenograft), and group 3 (orange circle: control/no treatment). $B I C$ was significantly higher among sites in group 2 compared to those in group I $(P<0.05)$ and group $3(P<0.01)$. ${ }^{*} P<0.05 ;{ }^{\dagger} P<0.01$.

between sites in group $1(0.257 \pm 0.232 \mathrm{~mm})$ compared to group 3 (control group) (Figs. 3A, 4, and 5).

\section{$B B V$}

The mean BBV was significantly higher around dehiscence defects in group $2\left(67.87 \pm 19.83 \mathrm{~mm}^{3}\right)$ compared to group $1\left(42.47 \pm 6.78 \mathrm{~mm}^{3}\right)(P<0.05)$ and group $3\left(19.12 \pm 4.06 \mathrm{~mm}^{3}\right)(P<0.001)$. There was no significant difference in the mean BBV between group $1\left(42.47 \pm 6.78 \mathrm{~mm}^{3}\right)$ and group 3 $\left(19.12 \pm 4.06 \mathrm{~mm}^{3}\right)$ (Figs. 3B, 4, and 5).

\section{VBH}

The mean VBH was significantly higher around dehiscence defects in group $2(6.36 \pm 1.37 \mathrm{~mm})$ compared to the control group (group 3) $(0.00 \pm 0.00$ $\mathrm{mm})(P<0.001)$. The mean VBH was significantly higher around dehiscence defects in group 1 (3.91 \pm $2.68 \mathrm{~mm}$ ) compared to the control group (group 3) $(0.00 \pm 0.00 \mathrm{~mm})(P<0.05)$. VBH was significantly higher in group $1(3.91 \pm 2.68 \mathrm{~mm})$ compared to group $3(0.00 \pm 0.00 \mathrm{~mm})(P<0.05)$. There was no significant difference in the VBH between group 1 

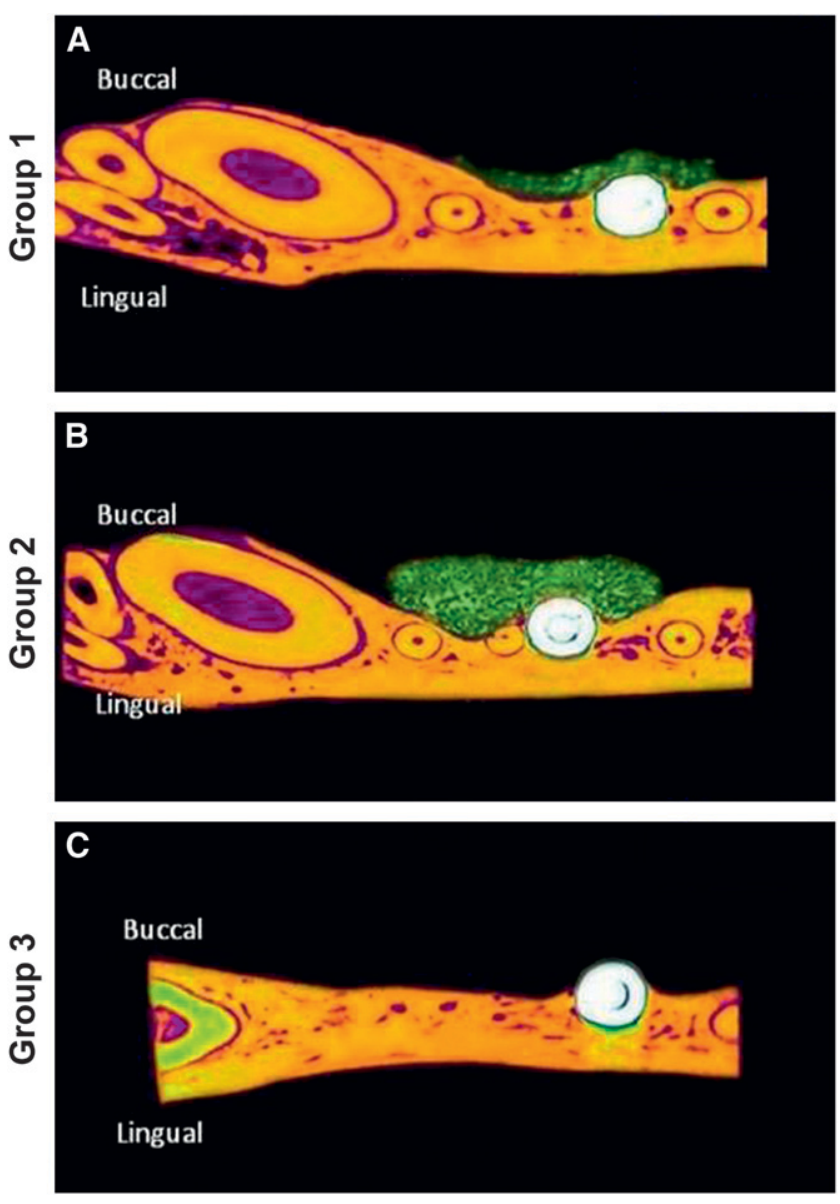

Figure 4.

A through C) A series of reconstructed axial microCT images illustrating the thickness of the newly formed buccal bone (green) around immediate implants with dehiscence defects in groups I through 3. D through F) A series of reconstructed sagittal microCT images illustrating the vertical height of the newly formed buccal bone around immediate implants with dehiscence defects in groups I through 3.
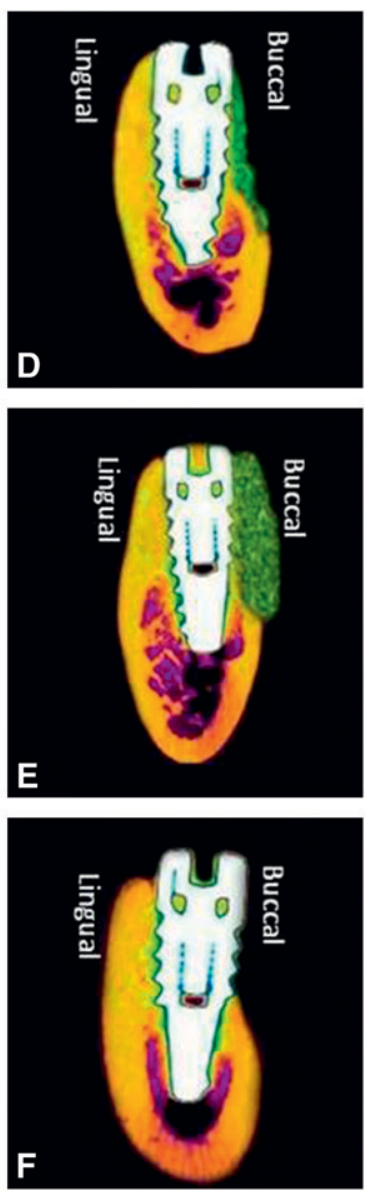

$(3.91 \pm 2.68 \mathrm{~mm})$ and group $2(6.36 \pm 1.37 \mathrm{~mm})$ (Figs. 3C and 4).

\section{BIC}

The mean BIC was significantly higher around dehiscence defects in group $2(67.25 \% \pm 13.42 \%)$ compared to that in group $1(36.25 \% \pm 12.78 \%)$ $(P<0.05)$ and group $3(30.25 \% \pm 7.27 \%)(P<0.01)$ (Figs. 3D and 4). There was no significant difference in the mean BIC among sites in group $1(36.25 \% \pm$ $12.78 \%$ ) and group $3(30.25 \% \pm 7.27 \%$ ) (Figs. 3D, 4 , and 5).

There was no significant difference in the BBT, BBV, $\mathrm{VBH}$, and $\mathrm{BIC}$ on the lingual surface of the implants among the three groups.

\section{DISCUSSION}

The present microcomputed tomographic results demonstrated that GBR around immediate implants with buccal dehiscence-type defects was enhanced when treated merely with xenograft and PDGF compared to when a CM was placed over the xenograft soaked in PDGF. These results are in accordance with studies ${ }^{27-32}$ that demonstrated that growth factors exhibit the potential to regenerate bone in dehiscence-type defects around implants. It has been hypothesized that the gel-like consistency of growth factors provides a spacemaking potential to the growth factor, and simultaneous use of graft material may hinder the collapse of the flap into the bone defect during the early healing phase. ${ }^{32}$ Likewise, in a recent systematic review, ${ }^{29}$ the authors reported that treatment of periodontal osseous defects with enamel matrix derivative (an amelogeninrich growth factor) is as effective as when resorbable membranes are used during GBR. Simion et al. ${ }^{16,18}$ hypothesized that barrier membranes obstruct the chemotactic effect of the growth factor on periosteal pluripotential mesenchymal cells. Similar results were reported by Kanou et al. ${ }^{33}$ This may be an explanation for our results that demonstrated a higher BBT, BBV, and BIC around dehiscence treated with PDGF and xenograft alone compared to those covered with CM after placement of PDGF and xenograft over the defect. However, additional studies are warranted to investigate the influence of barrier membranes on the periosteal pluripotential mesenchymal cells.

Several studies ${ }^{18-22}$ have shown that PDGF enhances periodontal regeneration by accelerating events, such as cellular chemoattraction, differentiation, and proliferation. Mott et al. ${ }^{34}$ used fluorescence effects to investigate the effect of bone graft soaked in PDGF on osteoblastic proliferation around rat calvaria defects. The results demonstrated that use of bone grafts soaked in PDGF significantly enhanced osteoblastic proliferation in the defect sites compared to sites merely treated with bone graft. ${ }^{34}$ In another study, Sanchez-Fernandez et al. ${ }^{27}$ tested the 


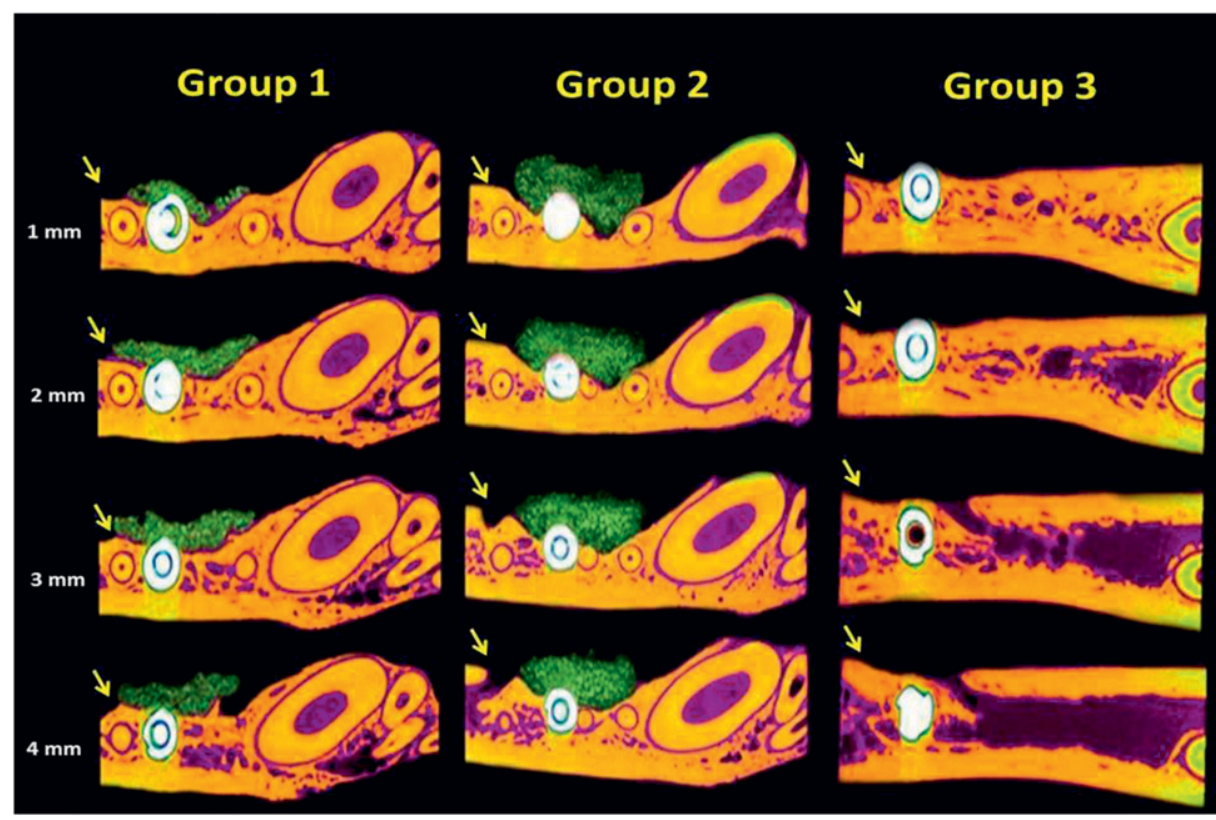

Figure 5.

A series of reconstructed axial images (at four different sections of I -mm intervals starting I mm below the cemento-enamel junction) illustrating the thickness of the newly formed buccal bone (green) among the three groups. In group 2 (PDGF+ xenograft), bone regeneration around immediate implants with dehiscence defects was significantly higher in group I (PDGF + xenograft $+C M)$ and group 3 (control/no treatment). Yellow arrows indicate the buccal surface.

hypothesis that osteoclasts can regulate the chemotaxis of osteoblasts. The results demonstrated that mature osteoclasts produce factors including the PDGF that attract osteoblasts toward sites with osseous defects, thereby promoting new bone regeneration in the target tissues. ${ }^{27}$ Similar results were reported by Park et al. ${ }^{35}$ Likewise, Howes et al. $^{36}$ reported that PDGF enhances demineralized bone matrix-induced cartilage and bone formation. The present microCT results support these studies $27,35,36$ because dehiscence defects treated merely with xenograft and PDGF displayed significantly more osseous regeneration compared to the defects treated with xenograft, PDGF, and CM. This reflects that the osteopromotive effects of PDGF are significant enough to induce new bone formation, and the contribution of a CM in this regard is redundant.

According to the present results, $\mathrm{VBH}$ and $\mathrm{BIC}$ were significantly higher around immediate implants where dehiscence sites were treated merely with xenograft and PDGF compared to sites covered with a CM after placement of PDGF and xenograft. A possible explanation in this regard may be extracted from a histologic study ${ }^{37}$ in which the authors demonstrated that CMs have a short half-life and are susceptible to resorption. Early resorption of a CM may contribute to impeding the osteogenic activity taking place in the space beneath the membrane.

\section{CONCLUSION}

Within the limits of the present microCT experiment, it is concluded that GBR around immediate implants with dehiscence defects using PDGF and xenograft alone resulted in higher BBT, BBV, VBH, and $\mathrm{BIC}$ than when performed in combination with a CM.

\section{ACKNOWLEDGMENTS}

This research was registered at the College of Dentistry Research Center, King Saud University, Riyadh, Saudi Arabia (\#NF 2364). The authors report no conflicts of interest related to this study.

\section{REFERENCES}

1. Araújo MG, Lindhe J. Dimensional ridge alterations following tooth extraction. An experimental study in the dog. J Clin Periodontol 2005; 32:212-218.

2. Al-Askar M, O’Neill R, Stark PC, Griffin T, Javed F, Al-Hezaimi K. Effect of single and contiguous teeth extractions on alveolar bone remodeling: A study in dogs [published online ahead of print December 15, 2011]. Clin Implant Dent Relat Res. doi: 10.1111/j.1708-8208.2011.00403.x.

3. Al-Shabeeb MS, Al-Askar M, Al-Rasheed A, et al. Alveolar bone remodeling around immediate implants placed in accordance with the extraction socket classification: A three-dimensional micro-computed tomography analysis. J Periodontol 2012;83:981-987.

4. Al-Hezaimi K, Levi P, Rudy R, Al-Jandan B, Al-Rasheed A. An extraction socket classification developed using analysis of bone type and blood supply to the buccal bone in monkeys. Int $J$ Periodontics Restorative Dent 2011;31:421-427.

5. Cardaropoli G, Araújo MG, Lindhe J. Dynamics of bone tissue formation in tooth extraction sites. An experimental study in dogs. J Clin Periodontol 2003;30:809-818.

6. Covani U, Cornelini R, Barone A. Bucco-lingual bone remodeling around implants placed into immediate extraction sockets: A case series. JPeriodontol 2003;74:268-273.

7. Schropp L, Wenzel A, Kostopoulos L. Impact of conventional tomography on prediction of the appropriate implant size. Oral Surg Oral Med Oral Pathol Oral Radiol Endod 2001;92:458-463.

8. Schropp L, Wenzel A, Kostopoulos L, Karring T. Bone healing and soft tissue contour changes following single-tooth extraction: A clinical and radiographic 12-month prospective study. Int $J$ Periodontics $R e$ storative Dent 2003;23:313-323.

9. Nevins M, Camelo M, De Paoli S, et al. A study of the fate of the buccal wall of extraction sockets of teeth with prominent roots. Int $J$ Periodontics Restorative Dent 2006;26:19-29. 
10. Covani U, Cornelini R, Calvo JL, Tonelli P, Barone A. Bone remodeling around implants placed in fresh extraction sockets. Int $J$ Periodontics Restorative Dent 2010;30:601-607.

11. Araújo MG, Sukekava F, Wennström JL, Lindhe J. Ridge alterations following implant placement in fresh extraction sockets: An experimental study in the dog. $J$ Clin Periodontol 2005;32:645-652.

12. Becker W, Becker BE. Guided tissue regeneration for implants placed into extraction sockets and for implant dehiscences: Surgical techniques and case report. Int $J$ Periodontics Restorative Dent 1990;10:376-391.

13. Becker W, Becker BE, Caffesse R. A comparison of demineralized freeze-dried bone and autologous bone to induce bone formation in human extraction sockets. J Periodontol 1994;65:1128-1133.

14. Nemcovsky CE, Artzi Z, Moses O, Gelernter I. Healing of dehiscence defects at delayed-immediate implant sites primarily closed by a rotated palatal flap following extraction. Int J Oral Maxillofac Implants 2000;15:550-558.

15. Goldstein M, Boyan BD, Schwartz Z. The palatal advanced flap: A pedicle flap for primary coverage of immediately placed implants. Clin Oral Implants Res 2002;13:644-650.

16. Simion M, Rocchietta I, Kim D, Nevins M, Fiorellini J. Vertical ridge augmentation by means of deproteinized bovine bone block and recombinant human platelet-derived growth factor-BB: A histologic study in a dog model. Int $J$ Periodontics Restorative Dent 2006;26:415-423.

17. Becker W, Lynch SE, Lekholm U, et al. A comparison of ePTFE membranes alone or in combination with plateletderived growth factors and insulin-like growth factor-I or demineralized freeze-dried bone in promoting bone formation around immediate extraction socket implants. J Periodontol 1992;63:929-940.

18. Nevins M, Al Hezaimi K, Schupbach P, Karimbux N, Kim DM.Vertical ridge augmentation using an equine bone and collagen block infused with recombinant human platelet derived growth factor-BB: A randomized single-masked histologic study in non-human primates. J Periodontol 2012;83:878-884.

19. Wang HL, Pappert TD, Castelli WA, Chiego DJ Jr, Shyr Y, Smith BA. The effect of platelet-derived growth factor on the cellular response of the periodontium: An autoradiographic study on dogs. J Periodontol 1994;65:429-436.

20. Wang HL, Miyauchi M, Takata T. Initial attachment of osteoblasts to various guided bone regeneration membranes: An in vitro study. J Periodontal Res 2002;37: 340-344.

21. Nevins ML, Camelo M, Schupbach P, Kim DM, Camelo $J M$, Nevins M. Human histologic evaluation of mineralized collagen bone substitute and recombinant platelet-derived growth factor-BB to create bone for implant placement in extraction socket defects at 4 and 6 months: A case series. Int $J$ Periodontics Restorative Dent 2009;29:129-139.

22. Nevins ML, Reynolds MA. Tissue engineering with recombinant human platelet-derived growth factor $\mathrm{BB}$ for implant site development. Compend Contin Educ Dent 2011;32:18, 20-27; quiz 28, 40.

23. Simion M, Rocchietta I, Dellavia C. Three-dimensional ridge augmentation with xenograft and recombinant human platelet-derived growth factor-BB in humans: Report of two cases. Int J Periodontics Restorative Dent 2007;27:109-115.

24. Simion $M$, Nevins $M$, Rocchietta I, et al. Vertical ridge augmentation using an equine block infused with recombinant human platelet-derived growth factorBB: A histologic study in a canine model. Int $J$ Periodontics Restorative Dent 2009;29:245-255.

25. Shiratori LN, Marotti J, Yamanouchi J, Chilvarquer I, Contin I, Tortamano-Neto P. Measurement of buccal bone volume of dental implants by means of conebeam computed tomography. Clin Oral Implants Res 2012;23:797-804.

26. Casati MZ, Sallum EA, Nociti FH Jr, Caffesse RG, Sallum AW. Enamel matrix derivative and bone healing after guided bone regeneration in dehiscence-type defects around implants. A histomorphometric study in dogs. J Periodontol 2002;73:789-796.

27. Sanchez-Fernandez MA, Gallois A, Riedl T, Jurdic P, Hoflack B. Osteoclasts control osteoblast chemotaxis via PDGF-BB/PDGF receptor beta signaling. PLoS One 2008;3:e3537.

28. Sculean A, Schwarz F, Miliauskaite A, et al. Treatment of intrabony defects with an enamel matrix protein derivative or bioabsorbable membrane: An 8-year followup split-mouth study. J Periodontol 2006;77:1879-1886.

29. Koop R, Merheb J, Quirynen M. Periodontal regeneration with enamel matrix derivative (EMD) in reconstructive periodontal therapy. A systematic review. J Periodontol 2012;83:707-720.

30. Boyan BD, Weesner TC, Lohmann CH, et al. Porcine fetal enamel matrix derivative enhances bone formation induced by demineralized freeze dried bone allograft in vivo. J Periodontol 2000;71:1278-1286.

31. Yukna RA, Mellonig JT. Histologic evaluation of periodontal healing in humans following regenerative therapy with enamel matrix derivative. A 10-case series. J Periodontol 2000;71:752-759.

32. Mellonig JT. Enamel matrix derivative for periodontal reconstructive surgery: Technique and clinical and histologic case report. Int $J$ Periodontics Restorative Dent 1999;19:8-19.

33. Kanou M, Ueno $T$, Kagawa $T$, et al. Osteogenic potential of primed periosteum graft in the rat calvarial model. Ann Plast Surg 2005;54:71-78.

34. Mott DA, Mailhot J, Cuenin MF, Sharawy M, Borke J. Enhancement of osteoblast proliferation in vitro by selective enrichment of demineralized freeze-dried bone allograft with specific growth factors. $J$ Oral Implantol 2002;28:57-66.

35. Park YJ, Lee YM, Lee JY, Seol YJ, Chung CP, Lee SJ. Controlled release of platelet-derived growth factor-BB from chondroitin sulfate-chitosan sponge for guided bone regeneration. J Control Release 2000;67:385-394.

36. Howes R, Bowness JM, Grotendorst GR, Martin GR, Reddi AH. Platelet-derived growth factor enhances demineralized bone matrix-induced cartilage and bone formation. Calcif Tissue Int 1988;42:34-38.

37. von Arx T, Broggini $\mathrm{N}$, Jensen SS, Bornstein MM, Schenk RK, Buser D. Membrane durability and tissue response of different bioresorbable barrier membranes: A histologic study in the rabbit calvarium. Int $J$ Oral Maxillofac Implants 2005;20:843-853.

Correspondence: Dr. Khalid Al-Hezaimi, Engineer Abdullah Bugshan Research Chair for Growth Factors and Bone Regeneration, College of Applied Medical Sciences, King Saud University, Riyadh 11411, Saudi Arabia. E-mail: hezaimik16@gmail.com.

Submitted March 3, 2012; accepted for publication April 4, 2012. 